\title{
DITRANSITIVIDAD MORFOLÓGICA: TIPOLOGÍA Y DEFINICIÓN DE LAS CONSTRUCCIONES APLICATIVAS*
}

\author{
Carmen Conti Jiménez \\ Universidad de Jaén \\ cconti@ujaen.es
}

\begin{abstract}
Resumen
Este artículo se centra en el estudio tipológico de las propiedades semánticas y sintácticas de los aplicativos benefactivos. Los aplicativos son afijos verbales que permiten codificar un argumento no subcategorizado por el verbo base como un argumento central del predicado. En este trabajo, pretendo demostrar que la aplicación no implica la transitivización del verbo o el aumento de su valencia, sino una regla de reescritura del Paciente. Con el fin de alcanzar una definición general de la aplicación, distinguiré entre dos tipos de aplicativos: los que modifican la valencia semántica del verbo base, por un lado, y los que tan sólo modifican la valencia sintáctica, por otro. En esta clasificación, seguiré algunas de las propuestas desarrolladas en Van Valin y LaPolla (1997) y Van Valin (2005), tales como los conceptos de transitividad semántica y sintáctica y la jerarquía de selección del Paciente.

PALABRAS CLAVE: aplicativos, beneficiario, macropapeles, procesos de modificación valencial, transitividad.
\end{abstract}

\begin{abstract}
This paper deals with the semantic and syntactic properties of benefactive applicatives from a crosslinguistic perspective. Applicatives are bound morphemes attached to a verb or an auxiliary that are employed to code a non-subcategorized argument as a core argument. In this paper, I will intent to demonstrate that application is not exactly a transitivizing or increasing valence process, but a rule by which the assignation of the undergoer is rewritten. In particular, I will propose a possible classification of applicatives in two different types: modifiers of the semantic valence, on the one hand, and modifiers of the syntactic valence, on the other. In this classification, I will follow some of the principles developed in Van Valin and LaPolla (1997) and Van Valin (2005), such as the notions of semantic and syntactic transitivity, and the selection of the undergoer.

KEY WORDS: applicatives, beneficiary, macroroles, transitivity, valence changing processes.
\end{abstract}

\section{Introducción}

Este artículo se centra en el estudio de las propiedades sintácticas y semánticas de los afijos aplicativos benefactivos en un corpus de veintisiete lenguas. La aplicación es un proceso derivativo que consiste en la adjunción de un afijo (prefijo o sufijo) a una base verbal generalmente transitiva. Dicho afijo, que se documenta en lenguas de distintas familias, sue-

* Este trabajo forma parte del proyecto personal titulado Estudio tipológico de las expresiones lingüisticas empleadas para la codificación de los papeles semánticos (beneficiado, perjudicado y receptor), que se desarrolló durante el 2004 en el Departamento de Lingüística de la Universidad de Buffalo (SUNY). El proyecto fue financiado por el MEC dentro del Programa de becas posdoctorales en el extranjero, referencia EX2003-0860. Agradezco al Prof. Robert D. Van Valin, Jr. su dedicación y ayuda durante mi estancia. Todos los errores que pueda contener este trabajo son sólo responsabilidad mía. 
le modificar el predicado mediante la adición de un argumento. Ese nuevo argumento, que ha de aparecer marcado como un objeto en la construcción aplicativa, puede desempeñar, según la lengua, el papel de instrumento, beneficiado, maleficiario, compañía o localizador.

En suma, los afijos aplicativos son, de acuerdo con Donohue (2003), morfemas ligados que se adjuntan a un verbo o a un auxiliar para codificar un argumento no subcategorizado como argumento central del predicado, según se ilustra en (1):

(1) Tukambesi (malayo-polinesia; Donohue, 2003: 221)

no-balu-ako te porai-no te bambai.

3REA.S/A-comprar-APL ARG.CTR prometida-3GEN ARG.CTR diadema

Lit. 'compró-APL.BEN( 'para') su prometida diadema'.

'Le compró una diadema a su prometida'.

Los afijos aplicativos han recibido la debida atención en lenguas como el niveano (cfr. Seiter, 1980), el zozil (cfr. Aissen, 1987), el kiñarruanda y el chicheva (cfr. Baker, 1988, Bresnan y Kanerva, 1989, Bresnan y Moshi, 1990) y el yaqui (cfr. Guerrero y Van Valin, 2004), por citar algunas, pero carecen hasta la fecha de un estudio tipológico que ofrezca una visión de conjunto del fenómeno que llamamos aplicación. A lo largo de este trabajo, veremos que algunos afijos verbales denominados aplicativos no siempre responden a los patrones sintácticos y semánticos que suelen caracterizar la aplicación en los estudios especializados, lo que me obligará a revisar la definición comúnmente aceptada de este proceso morfosintáctico. Siguiendo la idea general de mi artículo de (2004b), defenderé la pertinencia de dividir los modificadores de la valencia verbal en dos tipos: modificadores de la valencia semántica y modificadores de la valencia sintáctica. Añadiré a la propuesta anterior una interpretación del fenómeno como regla de rescritura del Principio A de selección del Undergoer en los verbos transitivos, siguiendo para ello el modelo de la Gramática del Papel y la Referencia de Van Valin y LaPolla (1997) y Van Valin (2005). Por último, plantearé la necesidad de que cada tipo de modificador valencial se adjunte en un nivel distinto de la gramática.

Mi intención en este artículo será, en resumen, alcanzar una definición lo más precisa posible que permita dar cuenta de la aplicación en distintas familias lingüísticas. Con este fin, revisaré el comportamiento semántico y sintáctico de las construcciones aplicativas en veintisiete lenguas, centrándome en la codificación del argumento beneficiado como objeto aplicado.

Este artículo consta de los siguientes apartados: en 2, se establece la filiación genética de las lenguas del corpus y se describe la tipología sintáctica de las lenguas que presentan afijos aplicativos. En 3, se revisan las características generales de la aplicación, como la restricción de transitividad (cfr. § 3.1), la posibilidad de alternancia sintáctica (cfr. § 3.2), el número de objetos aplicados en una misma oración (cfr. $\S 3.3$ ) y la selección del objeto primario (cfr. § 3.4), y se plantean los posibles problemas teóricos del fenómeno surgidos a raíz de los ejemplos del corpus (cfr. §3.5). En 4, se elabora una propuesta de clasificación para explicar satisfactoriamente el comportamiento de los afijos aplicativos en el corpus recurriendo a los conceptos de transitividad semántica y transitividad sintáctica (cfr. $\S \S 4.1-4.2$ ), y se realiza una posible representación de los afijos aplicativos en distintos niveles de la gramática (cfr. $\S 4.3)$. El apartado 5 contiene las conclusiones de este trabajo. 


\section{Tipos de lenguas para la estrategia aplicativa}

Los ejemplos de este artículo proceden de un corpus de cien lenguas en el que se han clasificado y analizado los distintos tipos de marcación para el beneficiado (p. e. Juan cocinó para sus padres), el maleficiado (p. e. Juan robó dinero a sus padres) y el receptor (p. e. Juan dio un regalo a sus padres) ${ }^{\prime}$. De esas cien lenguas, veintisiete presentan afijos verbales que codifican el argumento beneficiado como argumento central del verbo derivado. En el cuadro siguiente, aparecen recogidas las lenguas mencionadas con sus correspondientes fuentes bibliográficas:

\section{Cuadro 1. Filiación de las lenguas con afijos aplicativos}

\begin{tabular}{|l|l|}
\hline \multirow{3}{*}{ Amerindio } & $\begin{array}{l}\text { Barasano (tucana; Jones y Jones, 1991), quechua (andina; Weber, 1989), } \\
\text { sahaptín (penutí; Rude, 1997), sélico halkomelén (sélica; Gerdts, 1988), } \\
\text { tuscarora (iroquesa; Mithun, 1976), yaqui (yuto-azteca; Félix, 2000 y } \\
\text { Guerrero y Van Valin, 2004), yute (yuto-azteca; Southern Ute Tribe, } \\
\text { 1980), zozil (penutí, maya; Aissen, 1987) }\end{array}$ \\
\hline Áustrico & $\begin{array}{l}\text { Indonesio (malayo-polinesia; Sneddon, 1996 y Purwo, 1997), tagalo } \\
\text { (malayo-polinesia; Ramos, 1971), tinrin (malayo-polinesia; Osumi, } \\
\text { 1995), tukambesi (malayo-polinesia; Donohue, 2003) }\end{array}$ \\
\hline Caucásico & Abaza (caucásica; O'Herin, 2001) \\
\hline Chukoto-camchadal & Chukoto (chucoto; Dunn, 1999) \\
\hline Aleuto-esquimal & Groenlandés del oeste (aleuto-esquimal; Fortescue, 1984) \\
\hline Indo-pacífico & $\begin{array}{l}\text { Ava (transguineanana; Loving y McKaughan, 1973), barupu (macro- } \\
\text { skou; Donohue, 2003), bukiyipo (torricelli; Conrad, 1991), gadsupo } \\
\text { (transguineana; Frantz y McKaughan, 1973) }\end{array}$ \\
\hline Níger-cordofano & $\begin{array}{l}\text { Chicheva (níger-congo, bantú; Baker, 1988), kiñarruanda (níger-congo, } \\
\text { bantú; Kimenyi, 1980 y Baker, 1988), noni (níger-congo, bantú; Hyman, } \\
\text { 1981), noono (níger-congo, atlántica; Sonkka, 2000), suahilí (níger- } \\
\text { congo, bantú; Vitale, 1981) }\end{array}$ \\
\hline Sino-tibetano & $\begin{array}{l}\text { Lango (sudanesa del este; Noonan, 1992), nandi (sudanesa del este; } \\
\text { Creider y Creider, 1989) }\end{array}$ \\
\hline Meitéi (bárica; Bath y Ningomba, 1997 y Chelliah, 1997) \\
\hline
\end{tabular}

1 Para los criterios de distribución de los ejemplos del corpus, he seguido el trabajo de Rijkhoff y Bakker (1998). Estos autores defienden que el número de ejemplos que representa cada una de las familias lingüisticas ha de ser proporcional a su complejidad genética. Para la aplicación del método de Rijkhoff y Bakker (1998), he partido de la clasificación de Ruhlen (1987), que, pese a ser controvertida, permite que todos los grandes grupos lingüísticos estén representados en el corpus. En lo que respecta a la denominación de las lenguas, asumo, salvo contadas excepciones, la propuesta de Moreno Cabrera (2003). Las abreviaturas empleadas en este trabajo son las siguientes: $A=$ primer argumento de un verbo transitivo; $A B S=a b s o l u t i v o ; ~ A C=a c u s a t i v o$; $\mathrm{ADV}=$ adversativo o malefactivo; $\mathrm{ANT}=$ tiempo anterior; $\mathrm{APL}=$ aplicativo; $\mathrm{ARG}=$ argumento; $\mathrm{ASP}=$ aspecto; AUM=aumentativo; $A U X=$ auxiliar; $B E N=$ benefactivo o beneficiado; CAUS=causativo; $C E R T=$ certidumbre; $\mathrm{CL}=$ clítico; $\mathrm{CTR}=$ central; $\mathrm{DET}=$ determinante; $\mathrm{DIN}$ indicativo dinámico; $\mathrm{DIR}=$ directivo; $\mathrm{EP}=\mathrm{vocal}$ epentética; $E R G=$ ergativo; $E V I D D=$ =videncia directa; $F=$ femenino; $F U T=$ futuro; $G E N=$ genitivo; $H A B=$ habitual; $I C P=$ aspecto no completivo; IMP=imperativo; IMPF=imperfecto; INST=instrumental; INTR=intransitivo; $\mathrm{M}=$ masculino; $\mathrm{MED}=$ =medial; $\mathrm{N}=$ neutro; $\mathrm{NOM}=$ nominativo; $\mathrm{OBJ}=$ objeto; $\mathrm{OBL}=$ oblicuo; $\mathrm{OD}=$ objeto directo; $\mathrm{OI}=$ objeto indirecto; $\mathrm{P}=$ segundo argumento de un verbo transitivo; $\mathrm{PAS}=$ pasado; PASIV=pasiva; $\mathrm{PREP}=$ preposición; $\mathrm{PRES}=$ presente; 
El empleo de afijos aplicativos se documenta básicamente para la codificación de beneficiados, y, en menor medida, para la de receptores y maleficiados. En concreto, de las veintisiete lenguas que expresan el beneficiado mediante afijos verbales, sólo ocho codifican, además, el receptor, y siete, el maleficiado ${ }^{2}$. No se ha encontrado en el corpus ningún ejemplo en el que la construcción aplicativa introduzca de forma exclusiva al receptor.

La presencia de afijos benefactivos en las lenguas no está condicionada por factores de área o genéticos, ya que, como hemos visto en el cuadro anterior, dichos afijos se documentan en familias lingüísticas distribuidas por todo el globo. En cuanto al tipo sintáctico al que pertenecen las lenguas con construcciones aplicativas, la situación es bien distinta. Estas construcciones se documentan en lenguas en las que un argumento distinto del paciente/tema puede aparecer con las mismas marcas morfosintácticas que el segundo argumento de un verbo transitivo (de ahora en adelante, representado mediante P). Por esta razón, las construcciones aplicativas se atestiguan en lenguas de marcación de núcleo que pertenecen, además, al grupo de lenguas de objeto primario u objetividad escindida, pero nunca al de aquellas que siguen el patrón de objeto directo (OD)/objeto indirecto $(\mathrm{OI})$.

La distinción entre lenguas de $\mathrm{OD} / \mathrm{OI}$, lenguas de objeto primario y lenguas de objetividad escindida procede de Dryer $(1986,2003)$. Dicha clasificación se refiere al modo en que aparecen marcados los argumentos Tema (T) y Receptor $(R)$ en los verbos de tres argumen$\operatorname{tos}^{3}$. Dryer (2003) emplea las etiquetas $\mathrm{T}$ y $\mathrm{R}$ para referirse de forma literal o metafórica al segundo y tercer argumento de un verbo ditransitivo. El argumento Tema representa la entidad que experimenta un cambio de lugar o desplazamiento. El Receptor, por otro lado, no sólo incluye el papel de receptor propiamente dicho (o entidad que pasa a ser el nuevo poseedor del objeto desplazado), sino también el de destinatario (entidad que recibe el objeto desplazado, pero no implica posesión) y el de beneficiado del evento (el que recibe un beneficio del evento).

En las lenguas de objeto primario, el argumento $\mathrm{R}$ de los verbos ditransitivos aparece marcado como $\mathrm{P}$, esto es, el receptor presenta las mismas marcas morfosintácticas que el segundo argumento de un verbo de dos lugares. Véase el ejemplo siguiente:

(2) Yoruba (níger-congo; Dryer, 2003: 26)

Ajaki ko

$$
\frac{\text { Ayo }}{\mathrm{R}} \frac{\text { ni Yoruba. }}{\mathrm{T}} \text {. }
$$

Ajaki enseñó Ayo PREP yoruba

Lit. 'Ajaki enseñó Ayo yoruba'.

'Ajaki enseñó yoruba a Ayo'.

$\mathrm{PRF}=$ prefijo; $\mathrm{PL}=$ plural; $\mathrm{POSP}=$ posposición; $\mathrm{R}=$ =receptor; $\mathrm{REA}=$ modo realis; $\mathrm{S}=$ argumento de un verbo intransitivo; $\mathrm{SG}=$ singular; $\mathrm{SUJ}=$ sujeto; $\mathrm{T}=$ =tema (papel semántico); $\mathrm{TEM}=$ morfema temático; $\mathrm{TO} \mathrm{P}=$ tópico; $\mathrm{TR}=$ =transitivo; $\mathrm{U}=$ undergoer.

2 Las ocho lenguas que emplean aplicativos para BEN y R son el chicheva, el chukoto, el groenlandés del oeste, el indonesio, el sélico de Halkomelem, el tinrin, el tukambesi y el zozil. Las siete lenguas que emplean aplicativos para BEN y MAL son el abaza, el barasano, el barupu, el chicheva, el quechua, el meitéi y el zozil.

3 Dryer se refiere, en particular, a los verbos ditransitivos simples, esto es, a los casos de ditransitividad léxica que no precisan de un afijo verbal derivativo para marcar $T$ y $R$ como objetos. 
En la oración anterior, el receptor Ayo aparece marcado como P (marcación cero), mientras que lo enseñado, la lengua yoruba, aparece introducido como un oblicuo mediante la preposición ni (ni yoruba) $)^{4}$.

En cambio, en las lenguas de OD/OI, el receptor de los verbos ditransitivos se marca como un oblicuo (mediante adposiciones, caso dativo, entre otros), y no como $\mathrm{P}$, según se observa en (3):

\section{(3) Luisa dio un regalo a su amiga \\ $\mathrm{T} \quad \mathrm{R}$}

Las lenguas de objeto primario y las lenguas de OI/OD constituyen los dos patrones más relevantes en lo que se refiere a la marcación de $\mathrm{R}$ en los verbos de tres argumentos. Las lenguas de objeto primario, entendidas en un sentido restringido, esto es, como lenguas que expresan $R$ como $P$ en todos los verbos de tres lugares (Van Valin, 2005), son, sin embargo, poco numerosas. El patrón más representado entre las lenguas que expresan $\mathrm{R}$ como P está constituido por las lenguas que Dryer (2003) denomina de objetividad escindida (split-objectivity languages), en las que la clase de los verbos de tres lugares se divide en dos grupos: los verbos que presentan el patrón de $\mathrm{OD} / \mathrm{OI}(\mathrm{R} \neq \mathrm{P})$, por un lado, y los verbos con patrón de objeto primario $(\mathrm{R}=\mathrm{P})$, por otro. Sirva como ilustración de este tipo la lengua yaqui:

(4) Yaqui (yuto-azteca; Guerrero y Van Valin, 2004: 310)

Patrón de OD/OI (verbo 'vender')

a. Goyo Lupe-ta-u toto'i-ta nenka-k.

Goyo.NOM Lupe-AC-DIR heno-AC vender-PAS

'Goyo vendió heno a Lupe'.

Patrón de objeto primario (verbo 'dar')

b. Goyo Lupe-ta toto'i-ta miika-k.

Goyo.NOM Lupe-AC heno-AC dar-PAS

'Goyo dio heno a Lupe'.

Si bien Dryer (2003) clasifica las lenguas de objeto primario y de objetividad escindida a partir de lo que se puede considerar ditransitividad léxica (que se corresponde con aquellos verbos ditransitivos simples que codifican $R$ como $P$ sin necesidad de recurrir a un afijo verbal, como se ejemplifica en 5 para el lacota), cabe añadir como posible marcación de los patrones de objeto primario y objetividad escindida la ditransitividad morfológica, que se corresponde con aquellos verbos ditransitivizados mediante un afijo verbal derivativo, como se ilustra en (6) para el nandi:

4 Según Madugu (1982: 45), el receptor y el beneficiado se codifican en yoruba mediante el coverbo fún 'dar' (p. e. Báde fi iwé fun Tolú lit. 'Bade cogió libro dio Tolu', 'Bade le dio un libro a Tolu'). Algunos verbos admiten la promoción del receptor y el beneficiado, que aparecen, como en el ejemplo (2), marcados como P. La prep. $n i$ expresa el paciente/tema en estos casos. También se emplea esta preposición en expresiones locativas-directivas (p. e. lanzar algo a alguien), causativas (para el objeto original del verbo) e instrumentales. Véase Madugu (1982: 45) para esta cuestión. 
(5) Lacota (Van Valin, 2001)

wiyq ki mathó wa hokšila ki hená wičhá-Ø-kipazo.

mujer el oso un niño el aquellos 3PL-3SG.SUJ-mostrar

Lit. 'La mujer mostró los niños el oso'.

'La mujer mostró el oso a los niños'.

(6) Nandi (sudanesa; Creider y Creider, 1989: 126)

kí:sô:man-cì kípe:t la:kwé:t pû:kú:t.

PAS-leer-APL Kibet niño libro

'Kibet le leyó un libro al niño'.

Considero, por tanto, que la aplicación benefactiva es otra manifestación de los patrones de objeto primario $\mathrm{u}$ objetividad escindida para los verbos de tres lugares en los que $\mathrm{R}$ aparece marcado como $P$.

Téngase en cuenta, además, que a lo largo de este trabajo emplearé el concepto de objeto primario para referirme a la función sintáctica o relación gramatical que desempeña $\mathrm{P}$ o cualquier otro argumento que contrae las propiedades morfosintácticas y estructurales asociadas por norma general a este argumento. Esto implica, por un lado, que el sintagma que es objeto primario no sólo presenta un determinado tipo de marcación (por ejemplo, caso acusativo, marcación cero, etc.), sino que contrae también una serie de propiedades morfosintácticas y estructurales típicas del segundo argumento de un verbo transitivo, como la concordancia de objeto, el paso a sujeto de pasiva, etc. (remito al apartado 3 para un estudio detallado de estas propiedades).

En resumen, la aplicación benefactiva es un fenómeno típico de las lenguas que presentan un patrón de objeto primario o de objetividad escindida en los verbos de tres argumentos.

\section{Características generales de la aplicación}

Una vez esbozadas las cuestiones relativas a los condicionantes internos de la aplicación, expondré las características sintácticas y semánticas de este fenómeno. En los siguientes apartados, revisaré aquellas propiedades de la aplicación que aparecen invocadas repetidas veces en la bibliografía especializada, tales como la restricción de transitividad (cfr. § 3.1), la posibilidad de alternancia sintáctica (cfr. $\S 3.2$ ), las restricciones sobre el número de objetos aplicados en una misma oración (cfr. § 3.3) y la selección del objeto primario (cfr. § 3.4). Con este repaso pretendo demostrar que estos cuatro criterios de clasificación presentan una considerable variación interlingüística y que, en consecuencia, son insuficientes para definir este fenómeno desde una perspectiva tipológica.

\subsection{Restricción de transitividad}

Baker (1988: 256) defiende que los afijos aplicativos sólo se pueden adjuntar a una base verbal transitiva. Considera, asimismo, que en los casos en los que dichos afijos se adjuntan a bases intransitivas del tipo de cantar nos encontramos ante verbos de objeto cognado, capacitados para asignar Caso acusativo inherente (p. e. 'cantar una canción', 'cocinar una comida', etc.). 
Los aplicativos benefactivos del corpus presentan dicha restricción en lenguas como el ava, el barasano, el chukoto, el yaqui y el zozil, en las que sólo es posible adjuntar los afijos aplicativos benefactivos a verbos de dos lugares, y nunca a verbos monádicos (tengan o no una lectura de objeto cognado). Las lenguas que aplican la restricción de transitividad están, sin embargo, poco representadas en el corpus. Lo más habitual entre las lenguas manejadas es que la adjunción del afijo aplicativo benefactivo a verbos intransitivos sea factible, cuenten o no con la posibilidad de tener un objeto cognado. Los ejemplos de aplicativos con verbos intransitivos que admiten un objeto cognado se documentan en lenguas como el abaza, el barupu, el chicheva, el sélico, el tuscarora, y, posiblemente, el tinrin ${ }^{5}$, como se ilustra en (7):

(7) Barupu (macro-skou; Donohue, 2003: 125)

k-en-raivi-n-o-a [kendrajuinwa].

REA-1SG.F-cocinar-1SG-APL-3SG.M

'Cociné para él'.

La explicación de Baker (1988) para los casos en los que los aplicativos aparecen con verbos monotrantivos (en definitiva, verbos de objeto cognado, en opinión del autor) es poco satisfactoria, en cambio, para los aplicativos que se adjuntan a verbos como trabajar, según se ilustra a continuación:

(8) Yute (yuto-azteca; Southern Ute Tribe, 1980: 81)

ta'wa-ci mamá-ci wúúka-ku-xa.

hombre-SUJ mujer-OBJ trabajar-APL.BEN-ANT

'El hombre trabajaba para la mujer'.

(9) Quechua (andina; Weber, 1989: 155)

pay-ta aru-pa-yka-: karretera-ta.

él-OBJ trabajar-APL.BEN-IMPF-1 carretera-OBJ

'Estoy trabajando para él'.

'Trabajar' en las oraciones de (8-9) no implica un objeto cognado, de modo que difícilmente puede ser tratado como un verbo que asigna Caso acusativo. Es más, 'trabajar para alguien' es una actividad distinta de la de 'hacer un trabajo para alguien', pues, en el primer caso, el beneficio recibido por el destinatario es la acción misma de trabajar, mientras que, en el segundo, es un producto de ella. El propio Baker, en un trabajo posterior (cfr. Baker, 1996: 434), descarta la posibilidad de que los verbos intransitivos puros que admiten afijos aplicativos benefactivos tengan una posición argumental accesible para el tema (objeto cognado).

Opino, por otro lado, que hay pruebas suficientes para demostrar que los aplicativos benefactivos pueden adjuntarse a verbos intransitivos, admitan o no una interpretación tran-

5 El tinrin permite la adjunción de afijos aplicativos a bases transitivas e intransitivas, pero no se explicita en la fuente qué tipo de verbos intransitivos admite este proceso.

6 Sobre la restricción de transitividad, no se menciona cosa alguna en las gramáticas consultadas del gadsupo, ica, lango, meitéi, noni, noono, sahaptín, suahilí y tagalo. 
sitiva a través de un objeto cognado. La prueba decisiva de que la aplicación sobre verbos intransitivos no sólo es posible, sino que es, a su vez, distinta en muchos aspectos de la efectuada sobre verbos transitivos, nos la ofrece el hecho de que la aplicación benefactiva sobre un verbo intransitivo no aumenta la valencia del verbo base, esto es, el argumento beneficiado, pese a aparecer marcado como P, no contrae propiedades estructurales de objeto primario. Remito al apartado 3.5 para un tratamiento detallado de esta cuestión.

\subsection{Alternancia con la codificación de adjunto. Aplicativos dinámicos y aplicativos no dinámicos}

Las construcciones aplicativas de algunas lenguas, sean o no específicamente benefactivas, pueden alternar con una codificación de adjunto u oblicuo para el argumento aplicado. Donohue (2003) denomina dinámicas a aquellas construcciones aplicativas que alternan con una expresión de oblicuo o adjunto y no dinámicas, a aquellas otras en las que la alternancia sintáctica no es posible. Por ejemplo, el tukambesi tiene una construcción aplicativa benefactiva dinámica (cfr. 10), mientras que el zozil no permite la alternancia (cfr. 11):

(10) Tukambesi (malayo-polinesia; Donohue, 2003: 221)

Construcción aplicativa para el beneficiado

a. no-balu-ako te porai-no te bambai.

3REA.S/A-comprar-APL ARG.CTR prometida-3GEN ARG.CTR diadema

'Le compró una diadema a su prometida'.

Codificación de adjunto para el beneficiado

b. no-balu te bambai ako te porai-no.

3REA.S/A-comprar ARG.CTR diadema PREP ARG.CTR prometida-3GEN

'Compró una diadema para su prometida'.

(11) Zozil (maya; Aissen, 1987: 107)

meltzan-b-[o]-on lek $i$ garafon-e.

arreglar-APL.BEN-IMP-serieB.1SG bien el embudo-CL

'Arréglame bien el embudo'.

Aparte del tukambesi, tienen un sistema dinámico de aplicativos benefactivos el abaza (con la excepción de los aplicativos malefactivos, según O’Herin, 2001: 485), el bukiyipo, el chicheva, el ica, el indonesio, el meitéi, el sahaptín, el tagalo, el tinrin y el yaqui, mientras que el ava, el barasano, el barupu, el kiñarruanda, el quechua, el suahilí y el yute, además del zozil, presentan un sistema no dinámico?

Los sistemas dinámicos de aplicativos pueden verse condicionados por factores pragmáticos, ya que, por ejemplo, la construcción aplicativa se asocia con no poca frecuencia a la topicalización de un argumento cuyo referente ya ha aparecido en el discurso o es conocido por los participantes del acto de habla. En abaza, por ejemplo, los objetos aplica-

7 Desconozco cuál es el sistema del chukoto, el gadsupo, el hausa, el lango, el noni, el noono, el sélico y el tuscarora. 
dos deben ser definidos, según O'Herin (2001), mientras que, en tagalo, el objeto aplicado beneficiado presenta, frente al resto de los argumento, las marcas del tópico oracional, como se ilustra en $(12)^{8}$ :

(12) Tagalo (malayo-polinesia; Ramos, 1971: 6)

i-binili ng bata ng tinapay sa tindahan

APL-compró ARG.CTR niño ARG.CTR pan PREP tienda

ang nanay niya.

ARG.CTR.TÓP madre su

'El niño compró pan en la tienda para su madre'.

\subsection{Número de objetos aplicados. Construcciones de un objeto aplicado y construccio- nes de objetos aplicados múltiples}

Cuando el argumento beneficiado aparece como un objeto aplicado, se obtiene por lo general una secuencia de dos SSNN marcados como P (el objeto aplicado beneficiado y el SN paciente/tema). Gran parte de las lenguas del corpus presentan construcciones de objeto aplicado único, como se ha ilustrado hasta el momento en los ejemplos de los apartados anteriores. Lo más frecuente dentro de este grupo es que el argumento paciente/tema de la construcción aplicativa se marque o conserve la marcación de P; esto es, la marcación que le correspondería si fuera objeto del verbo base. Cabe la posibilidad, sin embargo, de que la promoción del argumento beneficiado mediante aplicación suponga un descenso del argumento paciente/tema en la jerarquía sintáctica, de tal suerte que dicho argumento ya no aparecerá marcado como $\mathrm{P}$, sino como un oblicuo. Así sucede, por ejemplo, en sélico y chukoto, como se observa a continuación:

(13) Sélico (sélica; Gerdts, 1988: 92)

ni $\theta \partial y-\partial t c-t-\partial s k^{w} \theta \partial$ swó?qe? ?a $\boldsymbol{k}^{w} \theta \partial$ snóx ${ }^{w} \partial t$.

AUX arreglar-APL-TR-3ERG DET hombre PREP DET canoa

'Le arregló la canoa al hombre'.

(14) Chukoto (Chukoto-camchadal; Dunn, 1999: 215)

t-ena-pela-y?a-n new-miryan coqar-a.

1SG-APL-dejar-TEM-3SG F-abuelo.3SG.ABS pan-INST

'Le dejé a la abuela pan'.

La aplicación puede ser también un proceso derivativo recursivo que da lugar a más de un objeto aplicado dentro de la misma oración. Por lo general, si la semántica oracional lo permite, pueden concurrir todos los objetos aplicados posibles en una lengua dada. En el corpus manejado, la aplicación puede ser recursiva en abaza y en kiñarruanda, como se ilustra en (15) para la primera lengua': 
(15) Abaza (caucásica; O'Herin, 2001: 484)

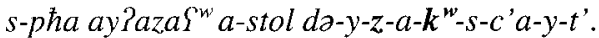

1SG-hija doctor la-mesa A3SG.HUM-PREF3PL.MASC-APL.BEN-PREF3SG.INANLOC.en-ERG1SG-poner -PRES-DIN

'Le puse a mi hija en la mesa al doctor'.

Según señala Donohue (2001), las construcciones con objetos aplicados múltiples son menos frecuentes en las lenguas que las construcciones con un solo objeto aplicado. El autor sugiere que las oraciones con más de un objeto aplicado requieren un mayor esfuerzo de procesamiento, lo que explicaría por qué en las lenguas se tiende a evitar que el predicado experimente la adjunción de más de un afijo aplicativo. Como veremos en el apartado 4.2, parece que, en efecto, la secuencia de más de un objeto aplicado complica la selección del objeto primario, ya que la aparición de más de un aplicativo origina un conflicto de rescritura de la valencia verbal.

\subsection{Objeto primario. Construcciones aplicativas asimétricas y simétricas}

Las construcciones aplicativas que constan de una secuencia de más de un SN marcado como P son ambiguas en lo que respecta a la selección del objeto de la cláusula. Partimos aquí de la idea comúnmente aceptada en lingüística de que, dentro de una misma oración, sólo un sintagma puede desempeñar la función de objeto primario. En el caso de las construcciones aplicativas, nos encontramos con al menos dos SSNN (en ocasiones, más de dos) candidatos a desempeñar dicha función sintáctica. No es de extrañar, por tanto, que la mayor parte de los estudios acerca de las construcciones aplicativas hayan versado sobre la cuestión de qué SN de los marcados como P es el objeto directo final (Seiter, 1980), recibe Caso acusativo inherente (Baker, 1988) o es seleccionado como undergoer o paciente (Van Valin y LaPolla, 1997), entre otras hipótesis.

En este trabajo, he aplicado varios diagnósticos para detectar qué SN marcado como $\mathrm{P}$ es el objeto primario de la construcción aplicativa benefactiva. Básicamente, he seguido los criterios manejados por Bresnan y Moshi (1990) para desambiguar los predicados aplicativos de las lenguas bantúes. Esos criterios se refieren al orden de palabras, subjetivización en la voz pasiva y control de la concordancia de objeto. En concreto, el objeto primario de la construcción aplicativa será seleccionado como sujeto en la voz pasiva, ocupará una posición adyacente al verbo (o la posición típica de los objetos en el orden de palabras) y controlará la concordancia de objeto en el verbo. Bresnan y Moshi (1990) establecen, además, dos tipos de objetos en las construcciones aplicativas de las lenguas bantúes, que tendré en cuenta para este trabajo: los objetos asimétricos, en los que tan sólo un SN exhibe las propiedades morfosintácticas y estructurales de objeto primario; y los objetos simétricos, en los que más de un $\mathrm{SN}$ puede contraer las propiedades de objeto primario.

A los criterios de Bresnan y Moshi (1990), he añadido algunos ofrecidos por Van Valin y LaPolla (1997) y Van Valin (2005) para detectar el argumento del predicado que desempeña el macropapel de undergoer o Paciente, dado que el objeto primario es, en los casos que nos conciernen, el argumento Paciente del predicado (remito al apartado 4.1 para este concepto). En resumen, los diagnósticos aplicados a los ejemplos del corpus fueron los siguientes: 
a) Propiedades morfosintácticas

- Orden lineal: el objeto primario de la construcción aplicativa ocupará u ocupará preferentemente la posición de $\mathrm{P}$.

- Control de la concordancia/referencia cruzada de objeto: el objeto primario de la construcción aplicativa controlará o podrá controlar la concordancia/referencia cruzada que contrae P.

b) Propiedades estructurales

- Sujeto de pasiva: el objeto primario de la construcción aplicativa será sujeto de la construcción pasiva. Esta prueba será relevante en el caso de aquellas lenguas en las que sólo $\mathrm{P}$ puede ser sujeto de pasiva. No será de interés en aquellas lenguas en las que, por ejemplo, un argumento marcado como oblicuo puede pasar a sujeto de pasiva de forma sistemática ${ }^{10}$.

- Pronominalización, reflexivización y reciprocalización: el objeto primario de la construcción aplicativa presentará las mismas restricciones que $\mathrm{P}$ en los procesos de pronominalización, reflexivización y reciprocalización. Este diagnóstico será relevante en aquellas lenguas en las que sólo A (primer argumento de un verbo transitivo), $\mathrm{S}$ (argumento de un verbo intransitivo) o $\mathrm{P}$ pueden pronominalizarse bajo las mismas condiciones. No será pertinente en aquellas lenguas en las que cualquier SN (A, S, P, oblicuo o adjunto) presente las mismas restricciones de pronominalización ${ }^{11}$.

No todos los diagnósticos citados determinan de igual modo qué $\mathrm{SN}$ es el objeto primario de la construcción aplicativa. Habitualmente, las propiedades estructurales se perfilan como diagnósticos fuertes en el corpus, mientras que las propiedades morfosintácticas tienden a ser débiles. La configuración de estas propiedades como diagnósticos fuertes o débiles es específica de cada lengua, como veremos en los siguientes apartados ${ }^{12}$.

\subsubsection{Orden lineal}

En las lenguas del corpus que presentan el orden VO, el objeto aplicado beneficiado tiende a ocupar la posición típica de $\mathrm{P}$, esto es, suele seguir inmediatamente al verbo y pre-

10 Algunas lenguas, como el japonés, admiten el paso a sujeto de pasiva de R pese a aparecer marcado con una posposición, según señala Kuno (1973: 348 y 349):

a. John ga Mary ni kunsyoo o atae-ta.

J. POSP.NOM M. POSP.OBL medalla POSP.AC dar-PAS

'Juan dio una medalla a Maria'.

b. Mary ga John ni kunsyoo o atue-rare-ta.

M. POSP.NOM J. POSP.OBL medalla POSP.AC dar-PASIV-ASP

Lit. 'María fue dada una medalla por Juan'.

11 Sigo a Comrie (1978) para las etiquetas S, A y P.

12 Los diagnósticos de objetividad no siempre han podido aplicarse con éxito en el corpus, ya que, por ejemplo, las propiedades estructurales no suelen aparecer descritas en las gramáticas. En otros casos, son las propias lenguas las que carecen de una o más de las propiedades citadas, como sucede en aquellas en las que no hay concordancia verbal de objeto. Cuando corresponda, se hará notar si una propiedad está ausente en la lenguas o no aparece citada en su fuente. 
ceder al objeto no aplicado, como se atestigua en indonesio, kiñarruanda, lango, sahaptín, tukambesi y yaqui. Valga como ejemplo el siguiente:

(16) Indonesio (malayo-polinesio; Purwo, 1997: 235)

John mem-beli-kan Mary buku itu.

Juan MEM-comprar-APL María libro ese

'Juan le compró un libro a María'.

Hay lenguas de orden VO en el corpus, como el nandi, el chicheva y el suahilí, en las que la posición de los sintagmas marcados como $P$ puede variar. La flexibilidad en el orden parece depender de los rasgos de animación de los SSNN, de modo que el SN animado tiende a seguir al verbo, como se observa en (17a) para el chicheva, si bien es posible el orden T-R (cfr. 17b):

(17) Chicheva (bantú; Baker, 1988: 229 y 237)

a. mbidzi zi-na-perek-er-a nkhandwe msampha.

cebras 3SG.SUJ-PAS-entregar-APL-ASP zorro trampa

'Las cebras entregaron la trampa at zorro'.

b. mlimi a-ku-i-dul-ir-a mitengo nkhandwue.

granjero 3Sg.SUJ-PRES-3SG.OBJ-cortar-APL-ASP árboles zorro

'El granjero está cortando árboles para el zorro'.

Poco se puede decir acerca de la posición del objeto aplicado en las lenguas OV del corpus. El objeto aplicado beneficiado suele preceder al objeto no aplicado, de modo que es el SN paciente/tema el que ocupa una posición adyacente al verbo, como se observa en yute:

(18) Yute (yuto-azteca; Southern Ute Tribe, 1980: 81)

ta'wá-ci mamá-ci sivạạtu-ci pâxá-kụ-xa.

hombre-SUJ mujer-OBJ cabra-OBJ matar-APL.BEN-ANT

'El hombre mató una cabra para la mujer'.

En conclusión, el diagnóstico del orden de palabras no es determinante para establecer qué SN es el objeto primario de la construcción aplicativa, con la salvedad, claro está, de las lenguas de orden fijo. En las lenguas de orden libre, la posición de los SSNN marcados como P puede ser reflejo de distintos factores. Como se ha señalado más arriba, en nandi, chicheva y suahilí, la posición típica de $\mathrm{P}$ la ocupa el argumento más relevante dentro de la jerarquía de la animación, y no necesariamente el argumento que desempeña la función de objeto primario. En el caso específico de las lenguas de orden OV, como el yute, hay cierta tendencia a que el SN paciente/tema, y no el objeto aplicado beneficiado, ocupe la posición adyacente al verbo.

\subsubsection{Control de la concordancia de objeto}

Dentro de las lenguas del corpus que tienen concordancia o correferencia con el argumento $\mathrm{P}$ en el verbo, encontramos dos posibles patrones en lo que respecta a las construcciones aplicativas benefactivas: el de las lenguas en las que el verbo concuerda obligatoriamente con el objeto aplicado benefactivo, como sucede en suahilí, según Vitale (1981) (cfr. 19), y en zozil, de acuerdo con Aissen (1987) (cfr. 20), y el de las lenguas en las que el verbo 
puede concordar bien con el objeto aplicado benefactivo, bien con el SN paciente/tema, como ocurre en chicheva, según Baker (1988) (cfr. 21):

(19) Suahilí (bantú; Vitale, 1981: 44)

ni-li-m-pik-i-a chakula Juma.

ISG-3SG-cocinar-APL.BEN comida Juma

'Cociné algo de comer para Juma'.

(20) Zozil (maya; Aissen, 1987: 107)

meltzan-b-[o]-on lek i garafon-e.

arreglar-APL-IMP-serieB.1SG bien el embudo-CL

'Arréglame bien los embudos'.

(21) Chicheva (bantú; Baker, 1988: 247)

amayi a-ku-mu-umb-ir-a mtsuko mwana.

mujer 3SG.SUJ-3SG.OBJ-moldear-APL-ASP jarra.de.agua niño

'La mujer está moldeando una jarra de agua para el niño'.

La concordancia de objeto es una prueba débil de objetividad en lenguas como el chicheva, mientras que se trata de un diagnóstico fuerte en aquellas otras en las que tan sólo uno de los sintagmas puede controlar la concordancia o la correferencia con el verbo, como sucede en suahilí y en zozil.

\subsubsection{Sujeto de pasiva}

La prueba del paso a sujeto de pasiva es determinante en numerosas lenguas para establecer qué SN marcado como $\mathrm{P}$ es el objeto primario de la oración. En la mayoría de las construcciones analizadas (así en chicheva, indonesio, sahaptín y yaqui, por ejemplo), el objeto aplicado beneficiado es seleccionado obligatoriamente como sujeto de pasiva en la construcción aplicativa, y en ningún caso es posible seleccionar el paciente/tema como tal. Véase el ejemplo siguiente:

(22) Chicheva (bantú; Baker, 1988: 247)

mbidzi zi-na-gul-ir-idw-a nsapato (ndi kalulu).

cebras 3SG.SUJ-PAS-comprar-APL-PASIV-ASP zapatos (por liebre)

Lit. 'Las cebras fueron compradas unos zapatos (por la liebre)'.

En kiñarruanda, sin embargo, tanto el objeto aplicado beneficiado (cfr. 23a) como el paciente/tema (cfr. 23b) pueden pasar a sujeto de pasiva:

(23) Kiñarruanda (bantú; Baker, 1988: 265)

a. umukoobwa a-ra-andik-ir-w-a ibaruwa n'umuhuungu.

chica 3SG.SUJ-PRES-escribir-APL-PASIV-ASP carta por-chico

Lit. 'La chica fue escrita una carta por el chico'.

b. ibaruwa i-ra-andik-ir-w-a umukoobwa n'umuhuungu.

carta 3SG.N.SUJ-PRES-escribir-APL-PASIV-ASP chica por-chico

'La carta fue escrita para la chica por el chico'. 
La posibilidad de que ambos argumentos pasen a sujeto de pasiva en kiñarruanda ha motivado el análisis de estas construcciones como ejemplos de objetos simétricos dentro de distintos modelos teóricos. Dado que los dos argumentos marcados como $\mathrm{P}$ parecen tener identidad funcional y gramatical en lo que respecta a la prueba de la pasiva en kiñarruanda, Baker (1988) entiende que esta lengua permite asignar dos casos estructurales o doble Caso acusativo. Dentro del marco de la gramática relacional, por otro lado, se ha defendido la neutralización de las funciones de OD/OI en ejemplos como los anteriores. Cabe señalar, sin embargo, que esta identidad funcional y gramatical es sólo aparente, ya que, como se encargó de señalar Dryer (1983), existen otros diagnósticos morfosintácticos y estructurales distintos del de la pasiva que demuestran que hay asimetría entre el argumento paciente/tema y el objeto aplicado beneficiado en kiñarruanda. Uno de esos diagnósticos es el orden de palabras. Como vimos en el apartado 3.4.1, el kiñarruanda tiene un orden lineal estricto en el que el SN beneficiado de la construcción aplicativa, y no el paciente/tema, ocupa la posición de $\mathrm{P}$ en la oración. Por otro lado, el objeto aplicado beneficiado, y no el SN paciente/tema, experimenta los mismos procesos de pronominalización en el verbo que $\mathrm{P}$, como veremos en el siguiente apartado.

En suma, la prueba de pasivización no siempre puede entenderse como un diagnóstico fuerte de objetividad.

\subsubsection{Pronominalización, reflexivización y reciprocalización}

Otra de las pruebas de objetividad viene dada por los procesos de pronominalización, reflexivización y reciprocalización del objeto primario de la cláusula. En particular, nos interesa saber qué argumento de la construcción aplicativa benefactiva experimenta estos procesos, esto es, qué argumento aparece pronominalizado como lo hace $\mathrm{P}$ y cuál es reflexivizado y reciprocalizado como lo hace $\mathrm{P}$ cuando tenemos a $\mathrm{A}$ como controlador de la referencia.

El kiñarruanda, que en el diagnóstico de pasivización parecía comportarse como una lengua de objetos simétricos, presenta un comportamiento bien distinto en los procesos de pronominalización dentro de las construcciones aplicativas benefactivas. En esta lengua, los argumentos $\mathrm{A} / \mathrm{S}$ y el argumento $\mathrm{P}$ pueden aparecer en el verbo mediante distintos tipos de afijos pronominales. Como se ilustra en (24), el kiñarruanda cuenta con una serie especializada para los argumentos A/S y una segunda serie específica para el argumento P:

(24) Kiñarruanda (bantú) $)^{13}$

bi-zaa-gu-k-iza.

3SG.N.SUJ-FUT-2SG.OBJ-rico-CAUS

'(Ello) te hará rico'.

En las construcciones aplicativas benefactivas de esta lengua, el argumento paciente/tema no puede aparecer pronominalizado mediante la serie de afijos empleados para P, ya que tan sólo el argumento beneficiado puede experimentar dicho proceso, como se observa en $(25)^{14}$ :

13 Ejemplo de un informante. El argumento A/S siempre está representado en las formas finitas del verbo mediante un prefijo pronominal, cuyo comportamiento es, por tanto, parecido a los afijos de referencia cruzada.

14 El SN 'carta' habría sido pronominalizado en el verbo mediante el afijo $-b i-$. 
(25) (Baker, 1988: 265)

Yohani y-a-mw-oher-er-eje ibaruwa.

Juan 3SG.SUJ-PAS-3SG.OBJ-enviar-APL-ASP carta

'Juan le envió una carta'.

La pronominalización es, por tanto, un diagnóstico fuerte de objetividad en kiñarruanda.

Los procesos de reciprocalización y reflexivización pueden ser también diagnósticos fuertes en aquellas lenguas en las que las formas reflexivas y recíprocas sólo pueden representar al argumento beneficiado en la construcción aplicativa, como sucede, de acuerdo con Aissen (1987), en zozil. Como señala la autora (Aissen, 1987: 112), el sujeto de la construcción aplicativa no puede ser antecedente de un recíproco o reflexivo del paciente/tema, ya que sólo el objeto aplicado es susceptible de experimentar reflexivización o reciprocalización, como se ilustra en (26):

(26) Zozil (maya; Aissen, 1987: 111)

ch-[y]-av-be s-ba-ik.

ICP-serieA.3-plantar-APL serieA.3-sí mismo-PL

'Lo plantaron para sí mismos'.

En zozil, por tanto, es imposible expresar mediante una construcción aplicativa benefactiva una relación de reciprocidad o reflexividad del paciente/tema. Esto significa, por ejemplo, que no es codificable mediante aplicación una relación reflexiva como la expresada en El sacerdote se embelleció para los dioses, en la que el argumento A (el sacerdote) controla $\mathrm{P}(\mathrm{se})$.

En resumen, la relación de antecedente que establece el argumento A sobre los reflexivos y recíprocos (argumento P) es contraída por el argumento A y el argumento beneficiado en la construcción aplicativa, lo que evidencia su función de objeto primario en zozil.

\subsection{Balance y problemas}

Como he intentado demostrar a lo largo de los apartados anteriores, en cada una de las lenguas del corpus hay al menos un diagnóstico fuerte de objetividad que permite caracterizar al argumento beneficiado de la construcción aplicativa, y no al paciente/tema, como objeto primario de la oración.

En esta primera parte del trabajo he manejado las construcciones aplicativas del corpus que no suponen mayor problema para la definición general de aplicación que vimos en el apartado 1. Gran parte de las construcciones aplicativas benefactivas del corpus implican, en efecto, la incorporación al predicado de un argumento nuevo no subcategorizado por el verbo base. Ese argumento nuevo satisface, además, los diagnósticos fuertes de objetividad en las lenguas analizadas. Ahora bien, los ejemplos del corpus no siempre encajan en la concepción de la aplicación como un fenómeno de cambio valencial que comporta un aumento en el número de los argumentos del verbo. Como veremos a partir de ahora, dicha definición resulta insuficiente si queremos dar cuenta de las características reales de la aplicación benefactiva. Trataré a partir de este momento, por tanto, aquellos ejemplos del corpus que, al desmarcarse del comportamiento esperable dentro las construcciones aplicativas, nos obligan a revisar la naturaleza misma de la aplicación. 


\subsubsection{Aplicación sobre bases intransitivas}

Ya vimos en el apartado 3.1 que algunas lenguas permiten la adjunción de los aplicativos a verbos tanto transitivos como intransitivos, pero ¿son los efectos sintácticos y semánticos los mismos en los dos casos? Como mencioné en el apartado 3.1, la prueba más importante a favor de que la aplicación sobre verbos intransitivos puros es posible $y$, por tanto, de que la restricción de transitividad no es universal en los aplicativos consiste en que la aplicación sobre estos verbos, frente a la efectuada sobre verbos diádicos, no implica la generación de una posición argumental P. En efecto, el argumento aplicado de un verbo intransitivo aparece marcado como $P$, pero no desempeña la función de objeto primario, lo que significa que el objeto aplicado no contrae las propiedades morfosintácticas y estructurales que repasamos en 3.4. Así sucede, por ejemplo, en abaza, como apunta O'Herin (2001: 483). De acuerdo con el autor, los verbos intransitivos con prefijos aplicativos benefactivos no modifican la valencia verbal, como prueba el hecho de que el sujeto aparezca registrado en el verbo mediante la serie de prefijos absolutivos, en lugar de los ergativos. Véase el ejemplo de (27):

(27) Abaza (caucásica; O'Herin, 2001: 483)

$y-h-z \partial-S a h^{\prime \prime}-$ wan.

ABS.3PL-PREF.1PL-APL.BEN-bailar-IMPF

'Bailaron para nosotros'.

Si el verbo base de (27) hubiese experimentado un proceso de transitivización, el sujeto de la cláusula tendría que aparecer marcado en el verbo mediante la serie de afijos ergativos, como sucede con los verbos de dos argumentos.

La definición de los aplicativos como modificadores accesivos o aumentativos de la valencia verbal es, por tanto, imprecisa. No parece conveniente tratar los aplicativos como afijos transitivizadores, ya que su función principal no es la de aumentar el número de argumentos del verbo creando una posición argumental inexistente, sino la de rescribir o reasignar las propiedades de $\mathrm{P}$ a otro argumento distinto de $\mathrm{P}$. Para ello, es básico que el verbo base conste de una posición argumental $P$ que pueda ser rescrita por el afijo aplicativo. Cuando el verbo carece de esa posición, como ocurre en los intransitivos puros, el afijo aplicativo tan sólo marca el argumento aplicado como objeto, pero no le otorga el rango sintáctico de objeto primario.

Cabe preguntarse a continuación cómo puede afectar esta nueva definición del fenómeno a los distintos patrones de lenguas en lo que respecta a la restricción de transitividad, esto es, por qué hay lenguas que presentan la restricción de transitividad y por qué otras carecen de ella. Si la aplicación se concibe como una regla de rescritura de $\mathrm{P}$, se sigue lógicamente que haya lenguas en las que los aplicativos sólo sean posibles con verbos en los que existe dicha posición argumental. En estas lenguas, además, es esperable que la aplicación que rescribe $P$ tenga una finalidad sintáctica, esto es, que el argumento marcado como tal pase a desempeñar la función de objeto primario. En el caso de las lenguas en las que los aplicativos también pueden adjuntarse a bases verbales intransitivas puras, la aplicación no puede rescribir una posición argumental inexistente. Con este tipo de verbos, la aplicación se circunscribe a la marcación del argumento aplicado como P. Carezco de una explicación convincente que 
permita interpretar por qué la aplicación supera los límites de la transitividad y se extiende a los verbos intransitivos. Cabe suponer, por ejemplo, que la aplicación no sólo se concibe como una regla de rescritura, sino también como un resorte morfosintáctico que permite ascender en la jerarquía pragmática y semántica a un argumento típicamente humano. Se puede decir, por tanto, que los beneficiados aplicados con verbos intransitivos son más topicales que los beneficiados adjuntos y más prominentes en la jerarquía semántica, pues el verbo derivado incluye el beneficiado entre sus argumentos centrales.

Suponiendo, pues, que la idea de que la aplicación es una regla de rescritura de P sea correcta, podríamos explicar por qué no se documentan lenguas en las que los afijos aplicativos se adjunten exclusivamente a verbos monovalentes: resulta ilógico que una regla de rescritura de $\mathrm{P}$ se aplique sólo sobre verbos que carecen de dicho argumento.

\subsubsection{Aplicativo benefactivo en indonesio}

Permítaseme cerrar esta sección con otra prueba a favor de la hipótesis de rescritura recurriendo para ello al afijo aplicativo benefactivo -kan del indonesio. Según Purwo (1997), este afijo no sólo se emplea para aplicar el argumento beneficiado, como se ilustra en (28), sino también para hacer descender en la jerarquía sintáctica al argumento receptor de verbos de transferencia, que aparece codificado en tales casos como un oblicuo, según se ilustra en (29):

(28) Indonesio (malayo-polinesia; Purwo, 1997: 235)

John mem-beli-kan Mary buku itu.

Juan TR-comprar-APL María libro ese

'Juan compró un libro para María'.

(29) (Purwo, 1997: 235)

John mem-beri-kan buku itu kepada Mary.

Juan TR-dar-APL libro ese PREP María

'Juan le dio el libro a María'.

Se considera que el argumento Mary de (29) ha descendido en la jerarquía sintáctica porque la primera vía de codificación del receptor con verbos de transferencia como dar es la de objeto primario, como se observa en (30):

(30) (Purwo, 1997: 235)

John mem-beri Mary buku itu.

Juan TR-dar.I María libro ese

'Juan le dio a María ese libro'.

Purwo (1997) trata el afijo - kan de (29) como un morfema derivativo que establece una relación morfosintáctica con el receptor oblicuo, y no con el tema. Esto es, en opinión del autor, el afijo - kan no afecta a la selección de P en (29). Esta interpretación de -kan, sin embargo, no permite clasificar el afijo dentro de los aplicativos según la definición tradicional del fenómeno, ya que -kan no incorpora un argumento nuevo en el predicado, sino que lo desplaza. 
$\mathrm{Si}$, siguiendo a Purwo, admitimos que -kan se emplea con verbos de transferencia para hacer descender en la jerarquía al receptor, entonces deberíamos clasificar este morfema como un afijo periférico ${ }^{15}$, y no como un aplicativo. Sin embargo, el tratamiento de -kan como afijo periférico no permite establecer correspondencia alguna con el uso aplicativo de este morfema, que vimos ejemplificado en (28). Si, por el contrario, acudimos a la definición de la aplicación como una regla de reescritura de $\mathrm{P}$, entonces sí sería factible ofrecer una interpretación conjunta del uso de -kan tanto en (28) como en (29). En efecto, en las dos oraciones, - $k a n$ supone la rescritura de $\mathrm{P}$, haciendo que un argumento distinto adquiera las características asociadas típicamente al segundo argumento de un verbo transitivo. La diferencia radica en que, en (28), se rescribe $\mathrm{P}$ a favor del argumento beneficiado, mientras que en (29), se rescribe $\mathrm{P}$ a favor del argumento tema.

\section{Propuesta de clasificación}

\subsection{Modificadores de la valencia semántica y modificadores de la valencia sintáctica}

Con el fin de describir adecuadamente las construcciones aplicativas en general y las benefactivas en particular, distinguiré aquí entre dos tipos de valencia verbal, como hice, por otro lado, en (2004b) siguiendo a Van Valin y LaPolla (1997: 147). Estos autores tipifican la valencia verbal en valencia semántica y valencia sintáctica. La primera se refiere al número de argumentos semánticos que toma un verbo en su estructura lógica, mientras que la valencia sintáctica comprende los argumentos codificados morfosintácticamente. La valencia semántica se corresponde en cierta medida con la noción de estructura argumental, si bien la primera puede comprender en algunos casos un número mayor de argumentos ${ }^{16}$. En relación con estos dos conceptos, encontramos los de transitividad semántica y transitividad sintáctica (Van Valin, 2005). Un verbo es semánticamente transitivo cuando su valencia consta de dos argumentos, de los que el primero desempeña el macropapel de Actor y el segundo, el macropapel de Undergoer ${ }^{17}$. Los macropapeles de Actor y Undergoer, propuestos en Foley y Van Valin (1984), recogen toda una tradición previa de propuestas acerca de etiquetas generales o macrofunciones que engloban varios papeles semánticos (véase Conti, 2004a para un resumen). Las nociones de Actor y Undergoer son próximas a los protorroles de Dowty (1991), si bien las primeras se definen a partir de la posición que ocupan los argumentos en la estructura lógica del predicado ${ }^{18}$. Los macropapeles son etiquetas de interfaz entre

15 De acuerdo con Frank (1990), los afijos periféricos son afijos derivativos que introducen en el predicado como argumento requerido un beneficiado adjunto, como se muestra en el siguiente ejemplo:

Ica (chibcha; Frank 1990: 69)

kafé Pablo-se? k-ıngei?-na-rua ni.

café Pablo-POSP PERI-vender-DIST-1SG CERT

'Le vendí el café a Pablo'.

El beneficiado no aparece marcado en la cláusula como $\mathrm{P}$, sino como un adjunto (posp. se?).

16 Por ejemplo, el argumento instrumental se concibe como argumento central en la Gramática del Papel y la Referencia y, por tanto, forma parte de la valencia semántica del verbo

17 Para no llevar a error, mantendré el término inglés undergoer para referirme al macropapel.

18 De hecho, la representación argumental y la asignación de papeles semánticos en la Gramática del Papel y la Referencia debe mucho a los trabajos de Jackendoff (1976), (1987) y (1990). 
semántica y sintaxis y equivalen, hablando de modo muy general, a los dos argumentos de la predicación transitiva. Los macropapeles se definen estructuralmente, por tanto, y su selección determina la sintaxis de la oración. Dada una jerarquía de accesibilidad como la representada en (31), será Actor el argumento que aparezca más a la izquierda en la estructura lógica del predicado, y Undergoer, el que se sitúe más a la derecha:

(31) Jerarquía del Actor-Paciente (Van Valin y LaPolla, 1997: 146)

\begin{tabular}{|l|l|l|l|l|}
\hline \multicolumn{2}{|l|}{ Actor } \\
\hline $\begin{array}{l}\text { Arg. de } \\
\text { DO }\end{array}$ & $\begin{array}{l}\text { ler arg. de } \\
\text { do' }(. . .\end{array}$ & $\begin{array}{l}1^{\text {cr }} \text { arg. de } \\
\text { pred' }(x, y)\end{array}$ & $\begin{array}{l}2^{\circ} \text { arg. de } \\
\text { pred' }(x, y)\end{array}$ & $\begin{array}{l}\text { Arg. de un estado } \\
\text { pred }(x)\end{array}$ \\
\hline
\end{tabular}

$[\rightarrow=$ aumento en la realización de un argumento como macropapel]

En resumen, un argumento tendrá más posibilidades de ser Actor si es el primer argumento de un verbo de actividad (DO y do' en el lenguaje del modelo), mientras que sus posibilidades disminuyen cuanto más nos acercamos a una estructura predicativa estática, como pred' (x). En lo que respecta al Undergoer, un argumento tendrá más posibilidades de desempeñar este macropapel si forma parte de un predicado de estado monádico y menos, cuanto más se aleje de esta clase de estructura predicativa.

Los argumentos Actor y Undergoer presentan un tipo de marcación y unas características morfosintácticas y estructurales dependiendo de cada una de las lenguas. Los verbos semánticamente transitivos presentan por lo general un patrón sintáctico transitivo, ya que codifican el Actor y el Undergoer con los rasgos de marcación, morfosintácticos y estructurales correspondientes.

Una de las aportaciones más interesantes y más recientes del modelo de la Gramática del Papel y la Referencia es ofrecer un marco explicativo para aquellos casos de transitividad sintáctica en los que no existe transitividad semántica. Dentro de este modelo, en efecto, un argumento puede aparecer marcado como $\mathrm{P}$ en la oración, pero no ser verdaderamente el argumento que desempeña el macropapel de Undergoer en el predicado. En suma, un verbo puede presentar una valencia sintáctica transitiva, pero no ser semánticamente transitivo, como sucede, según veremos más abajo, con algunos predicados aplicativos.

Otra de las aportaciones relevantes de esta teoría es la repercusión de los conceptos de transitividad semántica, macropapeles, etc. en el estudio de los verbos de tres argumentos (véase específicamente el trabajo de Van Valin, 2001). En concreto, se plantea la cuestión de si los verbos de tres argumentos, que en algunas lenguas presentan construcciones de doble objeto, son o no semánticamente ditransitivos; esto es, si hay dos argumentos marcados como P, ¿cabe la posibilidad de que haya dos Undergoers dentro de la misma cláusula? La conclusión a la que llega Van Valin en distintos trabajos (cfr. Van Valin, 2001 y 2005) es que los verbos de tres lugares son siempre semánticamente transitivos, ya que tan sólo uno de los argumentos marcados como $\mathrm{P}$ es Undergoer del predicado. Las lenguas de objetos simétricos podrían plantear un serio revés a esta afirmación, pues parece que en estos casos más de un argumento distinto del paciente/tema puede optar a desempeñar el macropapel de Undergoer. Ahora bien, como vimos en el apartado 3.4, los llamados objetos simétricos de lenguas como el kiñarruanda son en verdad pseudo-simétricos, ya que uno de ellos presenta 
más propiedades morfosintácticas y estructurales asociadas a $\mathrm{P}$ que los otros $\mathrm{y}$, por tanto, tiene más posibilidades de acceder al macropapel de Undergoer y a la función de objeto primario.

Dentro de este modelo teórico, por tanto, la diferencia entre la transitividad semántica de un verbo de dos argumentos y la de un verbo triádico con más de un SN marcado como $P$ radica en que el segundo aplica un principio semántico de selección del Undergoer (de ahora en adelante, $U$ ) distinto del principio que opera en los verbos transitivos tradicionales. En suma, la diferencia esencial entre los verbos diádicos y los verbos triádicos no reside en su transitividad semántica, sino en el principio de selección de U. Según Guerrero y Van Valin (2004) y Van Valin (2005), la selección de U en los verbos de tres argumentos puede establecerse a partir de dos principios: a partir del Principio A, seleccionamos como U el argumento que se encuentra situado más a la derecha en la estructura lógica del predicado; a partir de la aplicación del llamado Principio B, seleccionamos como U el argumento que ocupa la segunda posición más a la derecha en la estructura lógica. En los verbos de tres argumentos, el Principio A da cuenta de la selección típica de $\mathrm{T}$ como $\mathrm{U}$ en las estructuras de $\mathrm{OD} / \mathrm{OI}$ (paciente/tema $=\mathrm{U}$ ), mientras que el Principio $\mathrm{B}$ da cuenta de la selección de $\mathrm{R}$ como $U$ en las estructuras de objeto primario (receptor $=U$ ).

La estructura lógica de un predicado que contiene un argumento benefactivo es la siguiente, siguiendo en parte la propuesta de Jolly (1991: 126) para la preposición for del inglés:

(32) Estructura Lógica de los verbos con argumento benefactivo (' $x$ hace algo con el propósito de que $y$ tenga $z$ ')

$\alpha$ PURP [BECOME have' $(y, z)]$

La variable $\alpha$ se corresponde con cualquiera de los tipos eventivos propuestos en Van Valin (2005). El argumento $y$ es el beneficiado y el argumento $z$ es el paciente/tema. El argumento $z$ puede ser una entidad o un evento.

Ejemplo: Juan preparó una tarta para Maria.

[do' (Juan, Ø)] CAUSE [BECOME baked' (tarta)] PURP [BECOME have' (María, tarta)]

Si aplicamos el Principio A a la selección de U en una estructura lógica como la de (32), el objeto de la cláusula será el argumento paciente/tema (variable $z$ ), mientras que el argumento beneficiado (variable $y$ ), que no recibe ningún macropapel, aparecerá marcado en la oración como un adjunto verbal. Los afijos aplicativos permiten la rescritura del principio de selección de $U$ del verbo base a favor del Principio B. Si aplicamos el Principio B en la selección del undergoer, el objeto de la cláusula será el argumento beneficiado (variable $y$ ). En estos casos, el argumento paciente/tema (variable $z$ ) carece de macropapel y su marcación en las lenguas puede ser de distinta naturaleza, como veremos en (33) más abajo.

Veamos, pues, cómo pueden afectar estas nociones al proceso de modificación valencial que ejercen los afijos aplicativos sobre distintas bases verbales. Los afijos aplicativos que se adjuntan a un verbo cuya valencia semántica es transitiva (Actor-Undergoer) rescriben el Principio A de selección de U, tal y como se expone a continuación: 
(33) Aplicación benefactiva sobre bases transitivas

Valencia semántica de un verbo TR: Actor-Undergoer

Regla de la aplicación benefactiva: rescríbase el Principio A a favor del Principio $\mathrm{B} \Rightarrow$ Valencia semántica del verbo derivado: transitiva (Actor-Undergoer, con selección de U mediante el Principio B).

El argumento que desempeña el macropapel U recibirá la marcación correspondiente en cada lengua (p. e. marcación cero, caso acusativo, caso absolutivo, adposición, etc.) y contraerá las propiedades morfosintácticas y estructurales que se espera de este argumento (paso a sujeto de pasiva, concordancia de objeto, adyacencia al verbo, etc.). La valencia sintáctica del verbo derivado puede ser de dos tipos: transitiva, si sólo el argumento U aparece marcado como objeto y el argumento que no desempeña ningún macropapel aparece bien como oblicuo (cfr. 14, que repito en 34a), bien incorporado en el verbo (cfr. 34b); o ditransitiva, si hay más de un argumento, además de $\mathrm{U}$, que recibe la marcación de objeto (cfr. 15, que repito en 35 ):

(34) Valencia sintáctica transitiva (Chukoto; Dunn, 1999: 215 y 226)

a. t-ena-pela-y?a-n yew-miryzn coqar-a.

1SG-APL-dejar-TEM-3SG F-abuelo.3SG.ABS pan-INST

'Le dejé a la abuela pan'.

b. (...) n-ena-qora-nm-a-qen yew?en (...).

$\mathrm{HAB}-\mathrm{APL}$-reno-matar-E-3SG esposa.ABS

'Mató un reno para su mujer'.

(35) Abaza (caucásica; O'Herin, 2001: 484)

$s-p \hbar$ a ayPaza ' $^{w} a-s t o l$ d $d z-y-z-a-k^{w}-s-c^{\prime} a-y-t$ '.

1SG-hija doctor la-mesa A3SG.HUM-PREF3PL.MASC-BEN-PREF3SG.INAN-LOC. en-ERG1SG-poner -PRES-DIN

'Le puse a mi hija en la mesa al doctor'.

Los afijos aplicativos que se adjuntan a bases verbales intransitivas no implican la reescritura del Principio A, ya que los verbos intransitivos puros y los inacusativos carecen de este principio de selección para la asignación de macropapel a su único argumento. La aplicación benefactiva sobre bases intransitivas se caracteriza, pues, por lo siguiente:

\section{(36) Aplicación benefactiva sobre bases intransitivas}

Valencia semántica de un verbo INTR: intransitiva (Actor o Undergoer). En el caso que nos concierne, parece que los verbos intransitivos que admiten aplicativos son sobre todo intransitivos puros, y rara vez inacusativos ${ }^{19}$. Por tanto, el argumento del verbo es preferentemente Actor.

Regla de la aplicación benefactiva: no hay Principio A que rescribir $\Rightarrow$ Valencia semántica del verbo derivado: intransitiva (Actor o Undergoer). 
El argumento aplicado, pese a no recibir macropapel, aparece marcado como P. Como vimos para el abaza, cuyo ejemplo repito en (37), la valencia sintáctica del verbo derivado es transitiva, pues el beneficiado aparece marcado como P:

(37) Abaza (caucásica; O’Herin, 2001: 483)

$y-\boldsymbol{h}-z \partial-9 a h^{w}-w a n$.

ABS3PL-PREF1PL-APL.BEN-bailar-IMPF

'Bailaron para nosotros'.

Dado que con verbos monovalentes la aplicación del beneficiado no supone una reestructuración de la valencia semántica de la base, el argumento marcado como objeto incumple las pruebas estructurales y morfosintácticas asociadas al argumento que desempeña el macropapel de U, como el paso a sujeto de pasiva, la concordancia de objeto, etc.

En conclusión, los afijos aplicativos son básicamente modificadores de la valencia semántica, pues reasignan U cuando el verbo base cuenta con el principio A de selección del undergoer. Al rescribir la valencia semántica, pueden darse dos procesos en la valencia sintáctica del verbo derivado: que la valencia sintáctica se conserve y continúe siendo sintácticamente transitiva, en cuyo caso el argumento paciente/tema del verbo base se codifica como oblicuo o aparece incorporado al verbo; o que la valencia sintáctica aumente y pase a ser sintácticamente ditransitiva, con dos o más de dos argumentos marcados como P. Cuando los aplicativos no pueden rescribir el Principio A, lo que sucede con bases monovalentes, estos afijos se comportan sólo como modificadores aumentativos de la valencia sintáctica (transitividad sintáctica), pues marcan el argumento aplicado como P, pero no le asignan las propiedades morfosintácticas y estructurales propias del argumento con el macropapel de U.

\subsection{Propuesta teórica y tipología de las construcciones aplicativas benefactivas}

Desde el momento en que la aplicación es un proceso de rescritura del principio de selección de $U$, su función esencial consiste en la modificación de la valencia semántica de verbos que tienen activo dicho principio. De ello se deriva que la aplicación sea un proceso morfosintáctico que acontece, en primer lugar, con bases verbales diádicas y que, en ocasiones y según la lengua, jamás excede los límites de la transitividad semántica (restricción de transitividad). En tanto que proceso de modificación valencial, sin especificación de una u otra clase de valencia, la aplicación puede extenderse a verbos intransitivos en determinadas lenguas, afectando tan sólo a la valencia sintáctica mediante la inserción de un argumento marcado como $P$.

La alternancia sintáctica entre construcciones aplicativas y codificación de oblicuo/ adjunto para el beneficiado es posible, pero no obligatoria, cuando el aplicativo es un modificador de la valencia semántica, ya que determinadas lenguas pueden hacer que ciertos verbos derivados sólo presenten un principio de selección de $\mathrm{U}$ (principio $\mathrm{B}$ ) y un único marco de codificación de U (como objeto aplicado). Sin embargo, la alternancia sintáctica es obligatoria cuando el aplicativo sólo modifica la valencia sintáctica del verbo, pues los dos marcos de la alternancia se emplean con fines pragmático-discursivos (el referente denotado por el objeto aplicado es conocido por los interlocutores). 
Vimos también que, en caso de que una construcción aplicativa pudiera contener más de un objeto aplicado, tan sólo uno de ellos sería objeto primario de la oración. En efecto, la regla de reescritura del Principio A no es recursiva, lo que significa que sólo podemos modificar la valencia semántica una vez por oración. En las construcciones de objetos aplicados múltiples, sólo uno de los afijos aplicativos puede entenderse como regla de rescritura de U. El resto de los afijos son modificadores de la valencia sintáctica. Dada una secuencia de más de un objeto aplicado, el orden de preferencia en la rescritura de $U$ o, en otros términos, en la selección de un argumento como objeto primario ha sido estudiado para las lenguas bantúes por Bresnan y Kanerva (1989) y Bresnan y Moshi (1993). Estos autores llegan a la conclusión de que los objetos aplicados que desempeñan el papel de beneficiado tienen preferencia sobre los demás objetos aplicados para ser elegidos como objetos primarios, seguidos de los que desempeñan el papel de receptor, instrumento y locativo. Se arguye como primer motor de esta escala un principio de animación, según el cual los argumentos que denotan seres animados tienen preferencia para pasar a sujeto de pasiva o contraer la concordancia de objeto con el verbo. Parece, sin embargo, que también en estos casos se puede aplicar la hipótesis del Principio B en la selección de U. El argumento beneficiado ocuparía siempre la segunda posición más a la derecha en la estructura lógica del predicado, lo que nos obligaría a seleccionarlo como Undergoer, por delante de otros argumentos verbales.

\subsection{Propuesta de representación en un modelo de gramática}

Uno de los pilares básicos de la Gramática del Papel y la Referencia se asienta sobre la asunción de que la gramática no es modular ni tiene componentes aislables que podamos ordenar en el proceso de generación de estructuras lingüísticas. Aparte de las complicaciones que esta cuestión intrateórica puede generar en el estudio de los aplicativos y su adjunción en distintos niveles de la gramática, nos encontramos con que el modelo no ha desarrollado todavía una teoría estable sobre el componente morfológico y su relación con la sintaxis y el léxico.

El estudio de los afijos aplicativos me obliga, sin embargo, a considerar la posibilidad de que los modificadores de la valencia semántica y los modificadores que afectan exclusivamente a la valencia sintáctica operen en distintos niveles de la gramática y que, por tanto, la gramática se analice en componentes ordenados, tal y como han venido defendiendo desde hace muchos años las teorías modulares. Mi intención en este último apartado es proponer $\mathrm{o}$, mejor, sugerir una posible representación de los afijos aplicativos en distintos niveles.

Los aplicativos son afijos derivativos, prefijos o sufijos, que no cambian la categoría de la base a la que se adjuntan y cuya función básica es la rescritura de "Principio A". En cierta medida, estos afijos se comportan como los prefijos funcionales de las lenguas indoeuropeas (véase Felíu, 2003 para una tipología), pues, como éstos, los afijos aplicativos que modifican la valencia semántica del verbo base modifican la estructura argumental y temática del verbo. El proceso de adjunción de estos afijos debe situarse en un nivel o componente de la gramática en el que se lleve a cabo la selección de U y los procesos de rescritura de U. Estos procesos son anteriores a la marcación y a la codificación de los argumentos verbales, lo que permite postular que los aplicativos que modifican la valencia semántica se adjuntan en un nivel presintáctico. 
La clasificación de los afijos aplicativos que tan sólo modifican la valencia sintáctica del verbo es algo más compleja. Aunque, estrictamente hablando, estos afijos no afectan a la estructura argumental del verbo ni a su estructura temática, sí modifican lo que se denomina valencia sintáctica en la Gramática del Papel y la Referencia. Se puede admitir, por tanto, que los aplicativos que modifican sólo la valencia sintáctica son afijos funcionales, si bien, y a diferencia de los que modifican la valencia semántica, el proceso de adjunción a la base debe situarse fuera del léxico. Parece sensato, por tanto, ubicar su adjunción en el nivel sintáctico. Dado que los afijos aplicativos que modifican la valencia sintáctica determinan la marcación de los argumentos verbales, deberían ocupar una posición interna a la proyección verbal. Queda pendiente para futuras investigaciones determinar cuál es la posición exacta del predicado o SV en la que encontramos este tipo de afijo aplicativo.

\section{Conclusiones}

El objetivo fundamental de este trabajo ha sido demostrar que la función básica de los aplicativos no consiste en añadir un argumento central nuevo en el predicado derivado, sino en rescribir el Principio A del verbo base. Los aplicativos, por tanto, no transitivizan, en el sentido de que no crean una posición argumental $U$ ni tampoco dan lugar por sistema a construcciones con más de un argumento marcado como $\mathrm{P}$ (por tanto, no siempre son modificadores aumentativos o accesivos). Asimismo, he defendido que la aplicación tan sólo puede dejar en suspenso la rescritura del Principio A y modificar exclusivamente la valencia sintáctica en los casos en los que se adjunta a verbos intransitivos, esto es, cuando el verbo carece de dicho principio para la asignación de macropapel a su único argumento. Los aplicativos que se adjuntan a verbos intransitivos no varían la valencia semántica (el predicado nuevo sigue siendo semánticamente intransitivo), pero sí modifican la valencia sintáctica mediante la adición de un nuevo argumento marcado como P.

Por otro lado, se han propuesto dos posibles niveles de adjunción para los afijos aplicativos: un nivel presintáctico, en el caso de los afijos que modifican la valencia semántica del verbo (con verbos transitivos); y un nivel sintáctico, interno a la proyección verbal, en el caso de los aplicativos que sólo modifican la valencia sintáctica del verbo (con verbos intransitivos).

\section{Bibliografía}

Aissen, J. L. (1987): Tzotzil Clause Structure. Dordrecht, D. Reidel Publishing Company.

Baker, M. C. (1988): Incorporation. A Theory of Grammatical Function Changing. Chicago/Londres,

The University of Chicago Press.

Baker, M. C. (1996): The Polysynthesis Parameter. Nueva York, Oxford, Oxford University Press.

Bath, D. N. S. y M. S. Ningomba (1997): Manipuri Grammar. Munich, Lincom Europa.

Bresnan, J. y J. M. Kanerva (1989): "Locative inversion in Chichewa: a case study of factorization in grammar", Linguistic Inquiry, 20, págs. 1-50.

Bresnan, J. y L. Moshi (1990): "Object asymmetries in comparative Bantu Syntax", Linguistic Inquiry, 21, págs. 147-185.

Comrie, B. (1978): "Ergativity". En Lehmann, W. P. (ed.): Studies in the phenomenology of language. Sussex, The Harvester Press, págs. 329-394. 
Conti, C. (2004a): Papeles semánticos. Instrumento y comitativo. Madrid, Ediciones de la Universidad Autónoma de Madrid.

Conti, C. (2004b): "Valores diatéticos de los marcadores instrumentales y comitativos: enfoque tipológico", Revista Española de Lingüística, 34, 1, págs. 145-174.

Conrad, R. J. (con K. Wogiga) (1991): An outline of Bukiyip grammar. Canberra, Pacific Linguistics. Creider, Ch. A. y J. T. Creider (1989): A Grammar of Nandi. Hamburgo, Helmut Buske Verlag.

Chelliah, S. L. (1997): A Grammar of Meithei. Berlín, Nueva York, Mouton de Gruyter.

Donohue, M. (2001): "Coding choices in argument structure", Studies in Language, 25, 2, págs. 217 254.

Donohue, M. (2003): "Morphological Templates, Headedness, and Applicatives in Barupu", Oceanic Linguistics, 42, 1, págs. 112-143.

Dowty, D. (1991): "Thematic Proto-roles and Argument Selection", Language, 67, 3, págs. 547-619.

Dryer, M. (1983): “Indirect Objects in Kinyarwanda Revisited”. En Perlmutter, D. M. (ed.): Studies in Relational Grammar 1, Chicago, Londres, The University of Chicago Press, págs. 129-140.

Dryer, M. (1986): "Primary objects, secondary objects, and antidative", Language, 62, 4, págs. 808845.

Dryer, M. (2003): "Clause types", disponible en la página www.linguistics.buffalo.edu/people/faculty/dryer/dryer/dryer.htm.

Dunn, M. J. (1999): A Grammar of Chukchi. Tesis doctoral, Australian National University.

Félix, R. G. (2000): Las relaciones gramaticales en yaqui: Un análisis en el marco de la gramática de Rol y Referencia. Tesis de Maestría, Hermosillo, Universidad de Sonora.

Felíu, E. (2003): Morfología derivativa y semántica léxica: la prefijación de auto-, co- e inter-. Madrid, Universidad Autónoma de Madrid.

Fortescue, M. (1984): West Greenlandic. Sydney, Dover, New Hampshire, Crom Helm.

Frantz, Ch. y H. McKaughan (1973): "Gadsup Independent Verb Affixes". En McKaughan, H. (ed.): The Languages of the Eastern Family of the East New Guinea Highland Stock. Seattle, Londres, University of Washington Press, págs. 439-449.

Frank, P. (1990): Ika Syntax. Dallas, The Summer Institute of Linguistics y The University of Texas at Arlington.

Gerdts, D. B. (1988): Object and Absolutive in Halkomelem Salish. Nueva York, Londres, Garland Publishing, Inc.

Givón, T. (1994): "Nominalized clauses in Ute: the diachronic seesaw of finite structure". En Estrada, Z. (ed.): Memorias del II Encuentro de Lingüistica en el Noroeste, Tomo 1. Hermosillo, Universidad de Sonora, págs. 269-310.

Guerrero, L. y R. D. Van Valin, Jr. (2004): "Yaqui and the analysis of primary object languages", International Journal of American Linguistics, 70, 3, págs. 290-319.

Hyman, L. M. (1981): Noni Grammatical Structure. With special reference to verb morphology. Los Ángeles, Department of Linguistics, University of Southern California.

Jackendoff, R. (1976): "Toward an explanatory semantic representation", Linguistic Inquiry, 7, 1, págs. $89-150$.

Jackendoff, R. (1987): "The Status of Thematic Relations in Linguistic Theory", Linguistic Inquiry, 18, 3 , págs. 369-411.

Jackendoff, R. (1990): Semantic Structures. Cambridge, The MIT Press.

Jones, W. y P. Jones (1991): Barasano Syntax. Dallas, The Summer Institute of Linguistics y The University of Texas at Arlington.

Kimenyi, A. (1980): A Relational Grammar of Kinyarwanda. Berkeley, University of California Press.

Kuno, S. (1973): The Structure of the Japanese Language. Cambridge, Mass., Londres, The MIT Press. 
Loving, R. y H. McKaughan (1973): "Awa verbs, I: The Internal Structure of Independent Verbs". En McKaughan, H. (ed.): The Languages of the Eastern Family of the East New Guinea Highland Stock. Seattle, Londres, University of Washington Press, págs. 36-55.

Madugu, I. S. G. (1982): "The Yoruba ni-Object Construction in Pragmatic Perspective", Journal of African Languages and Linguistics, 4 , págs. 43-58.

Mithun, M. (1976): A Grammar of Tuscarora. Nueva York, Londres, Garland Publishing, Inc.

Moreno Cabrera, J. C. (2003): El universo de las lenguas. Clasificación, denominación, situación, tipología, historia y bibliografia de las lenguas. Madrid, Castalia.

Noonan, M. (1992): A Grammar of Lango. Berlín, Nueva York, Mouton de Gruyter.

O'Herin, B. (2001): "Abaza applicatives", Language, 77, 3, págs. 477-493.

Osumi, M. (1995): Tinrin Grammar. Honolulu, The University of Hawaii Press.

Purwo, B. K. (1997): "The Direct Object in Bi-transitive Clauses in Indonesian". En Givón, T. (ed.): Grammatical Relations. A Functionalist Perspective. Amsterdam, Filadelfia, John Benjamins, págs. 233-252.

Ramos, T. V. (1971): Tagalog for beginners. Honolulu, University of Hawaii Press.

Rijkhoff, J. y D. Bakker (1998): "Language sampling”, Linguistic Typology, 2-3, págs. 263-314.

Rude, N. (1997): "Dative Shifting and Double Objects in Sahaptin". En Givón, T. (ed.): Grammatical Relations. A Functionalist Perspective. Amsterdam, Filadelfia, John Benjamins, págs. 323-349.

Ruhlen, M. (1987): A guide to the world's languages. Stanford, Stanford University Press.

Seiter, W. J. (1980): Studies in Niuean Syntax. Nueva York, Londres, Garland Publishing, Inc.

Sneddon, J. N. (1996): Indonesian: A Comprehensive Grammar. Londres, Nueva York, Routledge.

Sonkka, M. (2000): A Descriptive Grammar of Noon. Munich, Lincolm Europa.

Southern Ute Tribe (1980): Ute Reference Grammar. Ignacio, The Southern Ute Press.

Van Valin, R. D. y R. J. LaPolla (1997): Syntax. Structure, Meaning, and Function. Cambridge, Cambridge University Press.

Van Valin, Jr., R. D. (2001): "The Role and Reference Grammar analysis of three-place predicates". Disponible en la página http://wings.buffalo.edu/linguistics/rrg.

Van Valin, R. D. (2005): Exploring the Syntax-Semantics interface. Cambridge, Cambridge University Press.

Vitale, A. J. (1981): Swahili Syntax. Dordrecht, Foris Publications.

Weber, D. J. (1989): A Grammar of Huallaga (Huánuco) Quechua. Berkley, Los Ángeles, Londres, University of California Press. 